\title{
Enhancement of reaction rates for catalytic benzaldehyde hydrogenation and sorbitol dehydration in water solvent by addition of carbon dioxide
}

\author{
MASAYUKI SHIRAI ${ }^{\mathrm{a}, \mathrm{b}, *}$, OSAMU SATO ${ }^{\mathrm{a}}$, NORIHITO HIYOSHI $^{\mathrm{a}}$ and \\ ARITOMO YAMAGUCHI ${ }^{\mathrm{a}}$ \\ ${ }^{a}$ Research Center for Compact Chemical System, National Institute of Advanced Industrial Science and \\ Technology (AIST), 4-2-1 Nigatake, Miyagino, Sendai, 983-8551, Japan \\ ${ }^{\mathrm{b}}$ Department of Chemistry and Bioengineering, Faculty of Engineering, IWATE University, 4-3-5 Ueda, \\ Morioka, Iwate, 020-8551, Japan \\ e-mail: mshirai@iwate-u.ac.jp
}

MS received 8 July 2013; revised 24 December 2013; accepted 26 December 2013

\begin{abstract}
The effect of pressured carbon dioxide on heterogeneous hydrogenation of benzaldehyde and homogeneous dehydration of sorbitol in water solvent was studied. Initial hydrogenation rates of benzaldehyde over a charcoal-supported palladium catalyst in water at $313 \mathrm{~K}$ were enhanced by the addition of carbon dioxide. The initial rate increased with an increase in carbon dioxide pressure and became a maximum at $5 \mathrm{MPa}$. Dehydration of sorbitol proceeded in water phase at $500 \mathrm{~K}$ and initial dehydration rates were enhanced by addition of $30 \mathrm{MPa}$ of carbon dioxide.
\end{abstract}

Keywords. High-pressure carbon dioxide; high-temperature liquid water; carbonic acid.

\section{Introduction}

We have succeeded to producing valuable chemicals with efficient chemical engineering in the twentieth century. However, we have to develop more efficient techniques for production of sustainable chemicals. Also, the technique should be more environmentally benign technique. ${ }^{1}$ In fine chemicals industries, organic solvents and inorganic acids are used in the enhancement of chemical reaction rates. Generally, organic solvents are hazardous and toxic, and much energy is required to remove organic solvents by distillation processes. Also, cost-consuming troublesome procedures are needed for neutralization of acid, and salts as by-products should be wasted. Application of highpressure carbon dioxide and water including supercritical conditions are studied as an alternative to organic solvent and inorganic acid., ${ }^{2,3}$ Savage's group proposed that a system with high-temperature liquid water under high-pressure carbon dioxide was effective for acid-catalysed reactions. ${ }^{4}$ Protons from carbonic acid molecules, which are formed by the reactions of water and carbon dioxide, can play a role as acid catalysts in the system (eq. 1). Carbonic acid is weak and its application in acid reactions is limited; however, neutralization processes after the reaction can be eliminated

*For correspondence by removal of carbon dioxide with depressurization procedure.

In this study, we report the application of highpressured carbon dioxide to the heterogeneous hydrogenation of benzaldehyde over a charcoal-supported ruthenium catalyst in water solvent and to the homogeneous dehydration of sorbitol in aqueous phase.

$$
\mathrm{CO}_{2}+\mathrm{H}_{2} \mathrm{O} \rightleftarrows \mathrm{H}_{2} \mathrm{CO}_{3} \rightleftarrows \mathrm{H}^{+}+\mathrm{HCO}_{3}^{-} \rightleftarrows 2 \mathrm{H}^{+}+\mathrm{CO}_{3}^{2-}
$$

\section{Experimental}

\subsection{Hydrogenation of benzaldehyde}

A charcoal-supported palladium catalyst (palladium loading: $5 \mathrm{wt} \%$ ) was purchased (Wako Pure Chemicals Industries Ltd.) and used as received. Benzaldehyde was also purchased (Wako Pure Chemicals Industries Ltd.) and used without purification.

Hydrogenation of benzaldehyde was carried out with a high-pressure reactor made of stainless steel. ${ }^{5} \mathrm{~A}$ diagram of the reaction system is depicted in figure 1 . Hydrogenation procedure is as follows. ${ }^{6}$ After loading of weighted amounts of catalyst, benzaldehyde, magnetic stirrer and distilled water into the reactor (inner volume: $50 \mathrm{~cm}^{3}$ ), the inside of the reactor was purged with argon to remove air and the reactor was heated 
with an oil bath. After the reactor was heated to the desired temperature, $1 \mathrm{MPa}$ of hydrogen was introduced and then quickly carbon dioxide was added through a liquid pump. Carbon dioxide pressure was estimated by subtracting hydrogen pressure from the total pressure. We defined the start of the reaction as the time when the introduction of carbon dioxide was finished. After the desired reaction time, the reactor was submerged into an iced water bath for cooling quickly. After depressurization, the slurry in the reactor was filtrated and products were recovered with acetone.

Quantitative analysis of products and unreacted benzaldehyde was conducted by a gas chromatograph equipped with a flame ionization detector (Agilent GC System 6890N) and a DB-WAX capillary column. Conversion and yield are defined as follows:

Conversion $(\%)=(1-($ the amount of benzaldehyde unreacted $(\mathrm{mol})) /($ initial amount of benzaldehyde $(\mathrm{mol}))) \times 100$. Yield $(\%)=($ the amount of each product obtained $(\mathrm{mol})) /($ initial amount of benzaldehyde $(\mathrm{mol})) \times 100$.

\subsection{Dehydration of sorbitol}

Sorbitol, which was purchased from Wako Pure Chemicals Industries Ltd., was used without purification.

Dehydration was carried out with a tube reactor made of a SUS $316 .^{7}$ A diagram of the reactor is depicted in figure 2. Dehydration procedure is as follows. ${ }^{8}$ After loading of $3 \mathrm{~cm}^{3}$ of aqueous sorbitol solution $\left(1.0 \mathrm{~mol} \cdot \mathrm{dm}^{-3}\right)$ into the tube reactor (inter volume: $6 \mathrm{~cm}^{3}$ ), the inside of the reactor was purged with argon to remove air. Dehydration under pressured carbon dioxide was operated as follows. After purging the inside with argon, the reactor was heated with a water bath $(323 \mathrm{~K})$. After purging with carbon dioxide, $30 \mathrm{MPa}$ of carbon dioxide was introduced into the reactor through a liquid pump. The reactor was submerged into a sand bath at $500 \mathrm{~K}$ for a given reaction time, and submerged into a water bath for cooling quickly to ambient temperature after the reaction. We estimated that the inside pressure at $500 \mathrm{~K}$ was $46 \mathrm{MPa}$ based on Charles's law. After depressurization by opening the valve, the mixture of the reactant and liquid products was taken out from the reactor with distilled water.

Quantitative analysis of liquid products and unreacted sorbitol was conducted by a high performance liquid chromatograph (GILSON, Inc.) with an evaporative light scattering detector (model 300S ELSD, SofTA Corporation) equipped with a Carbomix Ca NP5 column (Sepac Technologies Inc.). The products were identified by comparing the retention times with those of the standard materials. Conversion and yield are defined as follows;

Conversion $(\%)=(1-($ the amount of sorbitol unreacted $(\mathrm{mol})) /($ initial amount of sorbitol $(\mathrm{mol}))) \times 100$. Yield $(\%)=($ the amount of each product obtained $(\mathrm{mol})) /($ initial amount of sorbitol $(\mathrm{mol})) \times 100$.

\section{Results and discussion}

\subsection{Hydrogenation of benzaldehyde}

Table 1 shows conversion and selectivity values of benzaldehyde hydrogenation over $\mathrm{Pd} / \mathrm{C}$ for $30 \mathrm{~min}$ at $313 \mathrm{~K}$. GC analysis showed that products were only benzyl alcohol and toluene. Hydrogenation of benzaldehyde to benzyl alcohol and the following dehydroxylation of benzyl alcohol to toluene proceeded under the reaction conditions (scheme 1). Conversion under the neat (non-solvent) condition was $12.7 \%$ over $\mathrm{Pd} / \mathrm{C}$ for $30 \mathrm{~min}$ (table 1, entry 1). Conversion was changed by the addition of $5 \mathrm{~cm}^{3}$ of solvent to the hydrogenation system. The conversion order was water $>$ ethanol $>$ neat $>n$-heptane. Visual observation of the mixture of benzaldehyde, water, and $\mathrm{Pd} / \mathrm{C}$ at room temperature showed that two liquid phases of benzaldehyde and water were formed and $\mathrm{Pd} / \mathrm{C}$ existed in benzaldehyde phase. Condensation of benzaldehyde to $\mathrm{Pd} / \mathrm{C}$ and high hydrogen solubility to organic phase may cause the enhancement of the hydrogenation yield by addition of water.

We also studied the effect of carbon dioxide on the hydrogenation over $\mathrm{Pd} / \mathrm{C}$ in water. Addition of $3 \mathrm{MPa}$ carbon dioxide showed $53.4 \%$ conversion (table 1, entry 5), indicating that carbon dioxide enhanced hydrogenation rate. Solubility data of carbon dioxide in water showed that $\mathrm{pH}$ of water decreased with an increase in carbon dioxide pressure and became a constant value of 3 under more than $3 \mathrm{MPa}$ of carbon dioxide. ${ }^{6,9}$ Enhancement of benzyl alcohol yield by 


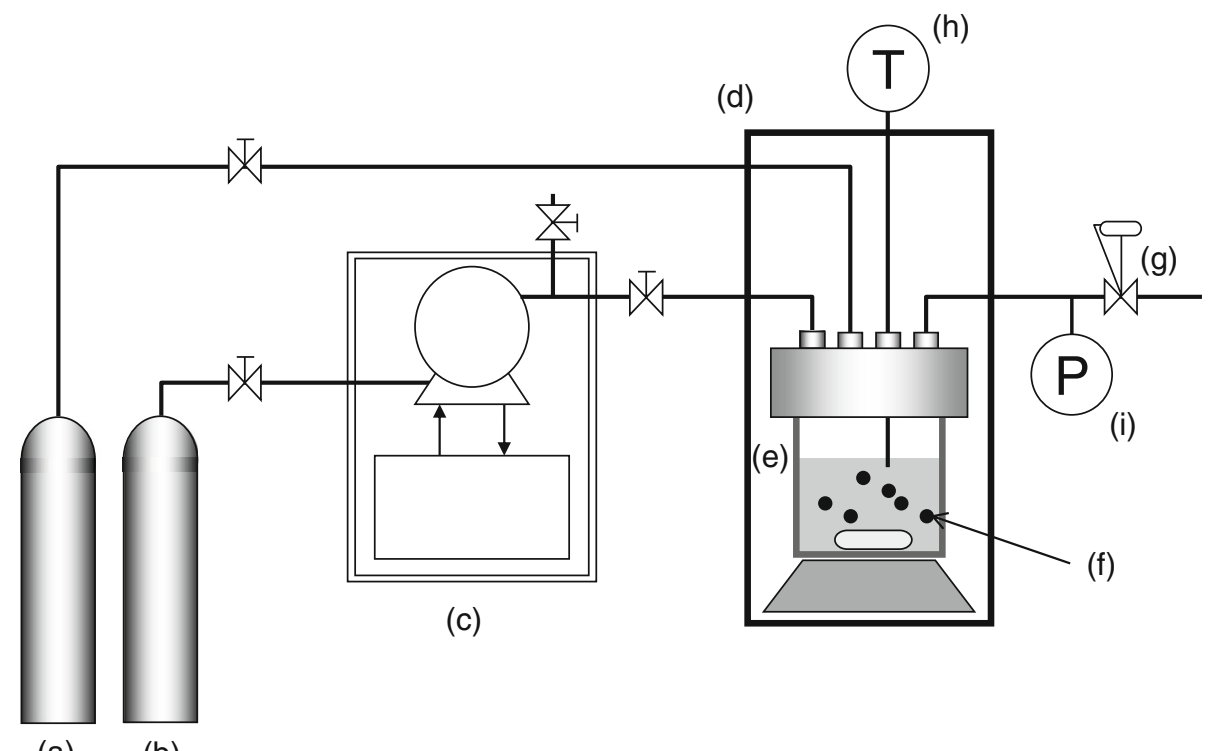

(a)

(b)

Figure 1. Apparatus for hydrogenation. (a) Hydrogen cylinder, (b) carbon dioxide cylinder, (c) liquid pump, (d) oven, (e) reactor, (f) catalyst, (g) back pressure regulator and (h) thermo couple.

addition of water and carbon dioxide would suggest that hydrogenation was enhanced by protons derived from carbonic acid. We also tested the effect of adding acetic acid $\left(0.05 \mathrm{~cm}^{3}\right)$ on the hydrogenation of benzaldehyde over the $\mathrm{Pd} / \mathrm{C}$ catalyst at $313 \mathrm{~K}$ (table 1 , entry 6).

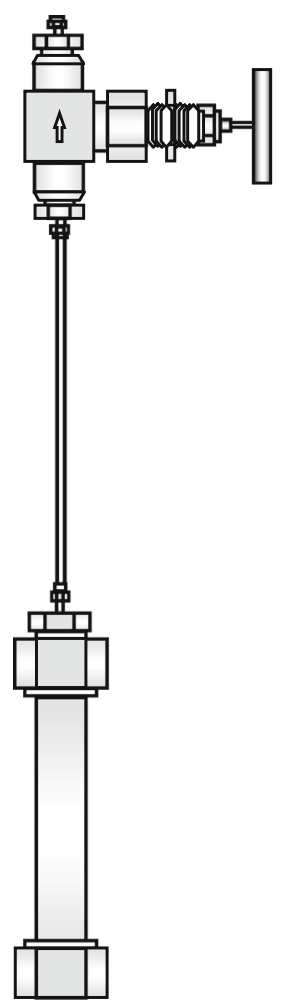

Figure 2. Apparatus for dehydration in high-temperature water.
Benzaldehyde conversion in the presence of $5 \mathrm{~cm}^{3}$ of aqueous acetic acid solution $(\mathrm{pH}=3)$ was $54.7 \%$ after $30 \mathrm{~min}$, which was close to that in the presence of $5 \mathrm{~cm}^{3}$ of water and $3 \mathrm{MPa}$ of carbon dioxide $(\mathrm{pH}=3)(53.4 \%)$, indicating that protons promoted hydrogenation. We have reported that addition of water and carbon dioxide enhanced initial reaction rates for acetophenone hydrogenation over a charcoalsupported palladium catalyst and discussed the probability that protons on palladium metal sites interacted with oxygen atoms on ketone groups in acetophenone molecules resulted in enhancement of initial reaction rates. It is probable that enhancement of the rate of benzaldehyde hydrogenation by adding carbon dioxide or acetic acid would result from interactions between oxygen atoms of aldehyde groups in benzaldehyde molecules and protons on the palladium surfaces.

We also studied the carbon dioxide pressure effect on the hydrogenation over $\mathrm{Pd} / \mathrm{C}$. Yields for $30 \mathrm{~min}$ at $313 \mathrm{~K}$ are shown in figure 3. Yields of benzyl alcohol for $30 \mathrm{~min}$ increased from $46.4 \%$ (0.1 MPa of argon atmosphere) to $65.6 \%$ (under $5 \mathrm{MPa}$ of carbon dioxide) with an increase in carbon dioxide pressure up to $5 \mathrm{MPa}$ and decreased with an increase in carbon dioxide pressure above $5 \mathrm{MPa}$. The main product was benzyl alcohol; however, minor by-product toluene, which could be obtained by dehydroxylation of benzyl alcohol, was formed. The yield of by-product toluene was less than $1 \%$ under less than $5 \mathrm{MPa}$ of carbon dioxide; however, by-product yield increased with increasing carbon dioxide pressure and it became $1.8 \%$ 
Table 1. Hydrogenation of benzaldehyde. ${ }^{a}$

\begin{tabular}{|c|c|c|c|c|}
\hline \multirow[t]{2}{*}{ Entry } & \multirow[t]{2}{*}{ Solvent ${ }^{b}$} & \multirow[t]{2}{*}{ Conversion(\%) } & \multicolumn{2}{|c|}{ Selectivity (\%) } \\
\hline & & & Benzyl alcohol & Toluene \\
\hline 1 & Neat (non-solvent) & 12.7 & 99.2 & 0.8 \\
\hline 2 & $n-\mathrm{C}_{7} \mathrm{H}_{16}$ & 6.3 & 97.7 & 2.3 \\
\hline 3 & $\mathrm{C}_{2} \mathrm{H}_{5} \mathrm{OH}$ & 25.4 & 99.2 & 0.8 \\
\hline 4 & $\mathrm{H}_{2} \mathrm{O}$ & 46.4 & 98.7 & 1.3 \\
\hline 5 & $\mathrm{H}_{2} \mathrm{O}+\mathrm{CO}_{2}{ }^{\mathrm{c}}$ & 53.4 & 98.7 & 1.3 \\
\hline 6 & $\mathrm{H}_{2} \mathrm{O}+\mathrm{CH}_{3} \mathrm{COOH}^{\mathrm{d}}$ & 54.7 & 98.4 & 1.6 \\
\hline
\end{tabular}

${ }^{\mathrm{a}}$ Hydrogen pressure $1 \mathrm{MPa}$, reaction temperature $313 \mathrm{~K}$, reaction time $30 \mathrm{~min}, \mathrm{Pd} / \mathrm{C} 0.003 \mathrm{~g}$, initial benzaldehyde $0.63 \mathrm{~g}$

${ }^{\mathrm{b}}$ Solvent $5 \mathrm{~cm}^{3}$

${ }^{\mathrm{c}}$ Water $5 \mathrm{~cm}^{3}$ and carbon dioxide pressure $3 \mathrm{MPa}$

${ }^{\mathrm{d}}$ Water $5 \mathrm{~cm}^{3}$ and acetic acid $0.05 \mathrm{~cm}^{3}$

under $15 \mathrm{MPa}$ of carbon dioxide. This result indicates that higher carbon dioxide pressure is unfavourable. It could be explained by the fact that conversion of benzaldehyde increased with an increase in carbon dioxide pressure up to $3 \mathrm{MPa}$ because of the increase in proton amounts; however, conversion increased further under more than $3 \mathrm{MPa}$ and then, decreased under more than $5 \mathrm{MPa}$ of carbon dioxide. We confirmed that two liquid phases were formed in the mixture of benzaldehyde and water in air at room temperature by direct visual observation; however, the phases could be changed under high pressure carbon dioxide. It is probable that benzaldehyde and water could be soluble in supercritical carbon dioxide phase (critical point $304.3 \mathrm{~K}$ and $7.38 \mathrm{MPa}$ ). Further investigation by direct phase observation under high-pressure condition will be done for detailed understanding.

The reaction profile of benzaldehyde hydrogenation over $\mathrm{Pd} / \mathrm{C}$ under $5 \mathrm{MPa}$ of carbon dioxide, which showed the maximum yield as a function of reaction time, was studied with the batch reaction system (figure 4). At the initial stage, in fact, when we immediately cooled the reactor to stop the hydrogenation reaction right after introducing $5 \mathrm{MPa}$ of carbon dioxide, $13.3 \%$ of benzyl alcohol yield was obtained. Benzaldehyde conversion and benzyl alcohol yield increased with an increase in time and became $93.0 \%$ and $91.0 \%$, respectively, at $60 \mathrm{~min}$. The by-product toluene

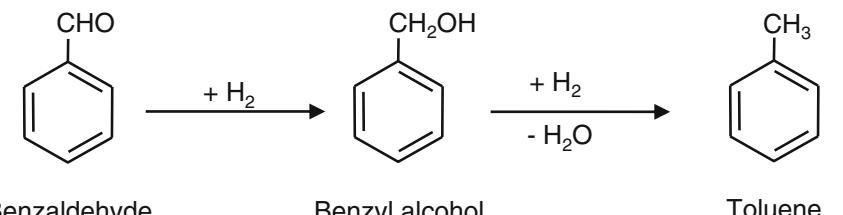

Scheme 1. Hydrogenation of benzaldehyde. yield was only $2.2 \%$ at $60 \mathrm{~min}$. The benzyl alcohol yield; however, decreased at higher conversion of benzaldehyde. Benzyl alcohol and toluene yields were 86.2 and $13.7 \%$, respectively, at $99 \%$ benzaldehyde conversion for $90 \mathrm{~min}$. To obtain high yield of benzyl alcohol, prolonged reaction time is undesirable.

\subsection{Dehydration of sorbitol}

A reaction profile for the treatment of aqueous dsorbitol solution (sorbitol concentration: $1.0 \mathrm{~mol} \cdot \mathrm{dm}^{-3}$ ) at $500 \mathrm{~K}$ under argon atmosphere is shown in figure 5(a). An yield of $1.8 \%$ of 1,4-d-anhydrosorbitol (1,4-AHSO) and $0.1 \%$ of 2,5-d-anhydrosorbitol (2,5AHSO) was obtained at $1 \mathrm{~h}$. Yield of 1,4-AHSO

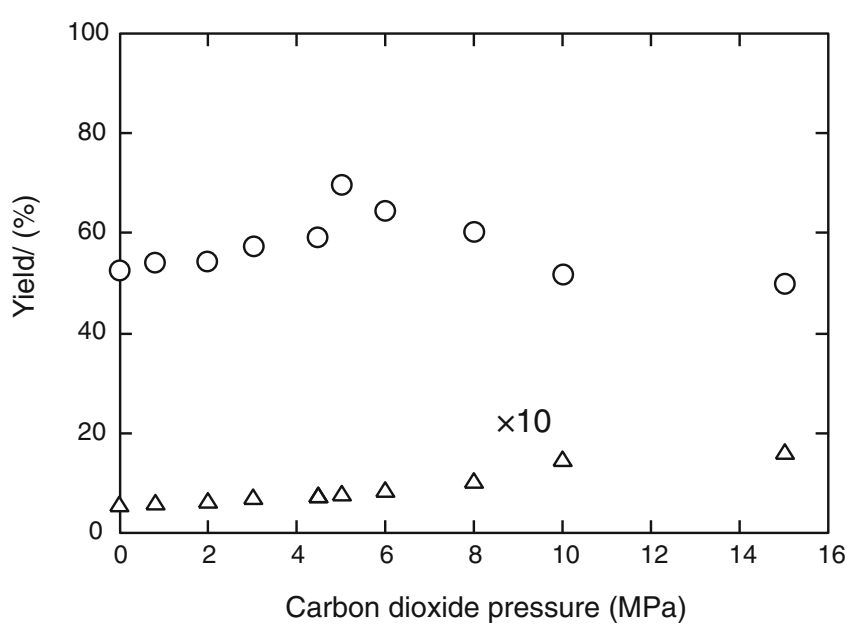

Figure 3. Carbon dioxide pressure effect on catalytic hydrogenation activity of benzaldehyde over charcoalsupported palladium catalyst in water ( $\mathrm{O}$ : benzyl alcohol and $\triangle$ : toluene). Amount of toluene is multiplied by 10 . Water solvent $5 \mathrm{~cm}^{3}$, catalyst $0.003 \mathrm{~g}$, reaction time $30 \mathrm{~min}$, reaction temperature $313 \mathrm{~K}$, hydrogen pressure $3 \mathrm{MPa}$ and initial benzaldehyde $6.0 \mathrm{mmol}$. 


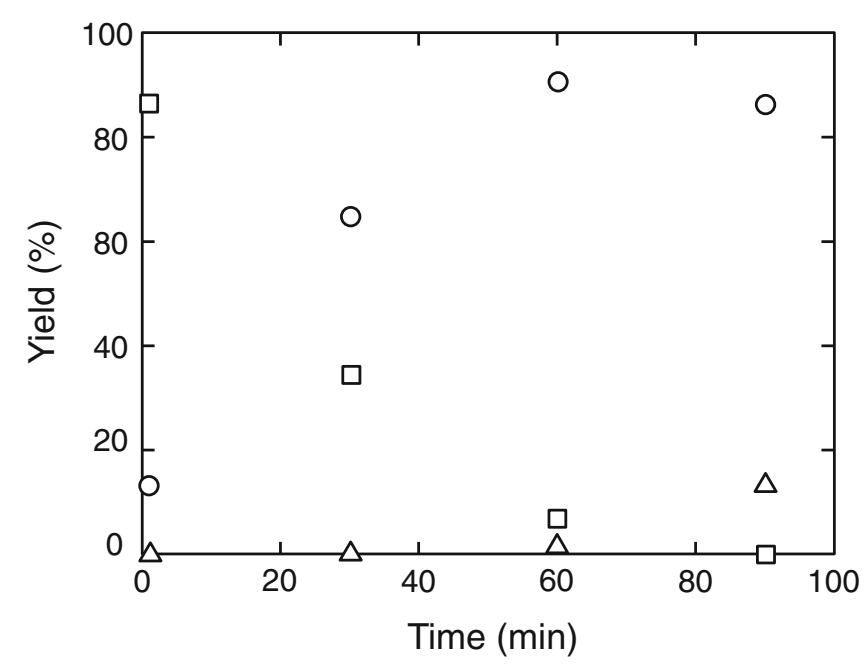

Figure 4. Catalytic hydrogenation of benzaldehyde over charcoal-supported palladium catalyst in water ( $\square$ : benzaldehyde, o: benzyl alcohol and $\triangle$ : toluene). Water solvent $5 \mathrm{~cm}^{3}$, catalyst $0.003 \mathrm{~g}$, reaction temperature $313 \mathrm{~K}$, hydrogen pressure $3 \mathrm{MPa}$, carbon dioxide pressure $5 \mathrm{MPa}$ and initial benzaldehyde $6.0 \mathrm{mmol}$.

increased with increase in time and $15.9 \%$ yield was obtained after $7 \mathrm{~h}$. In addition, $2.2 \%$ of isosorbide, which could be obtained by intramolecular dehydration of 1,4-AHSO, was obtained for the treatment of aqueous sorbitol solution for $7 \mathrm{~h}$. Yield of 2,5-AHSO did not increase so high and was only $0.9 \%$ after $7 \mathrm{~h}$. Three kinds of anhydrosorbitol could be formed by intramolecular dehydration from sorbitol (scheme 2); however, 1,5-d-anhydrosorbitol was not obtained. We have reported that sorbitol dehydration proceeded in water in the absence of inorganic acid at $523 \mathrm{~K} ;{ }^{10}$ figure 5(a) shows that dehydration of sorbitol proceeded in liquid water at lower temperature of $500 \mathrm{~K}$.

A reaction profile of aqueous d-sorbitol solution (sorbitol concentration: $1.0 \mathrm{~mol} \cdot \mathrm{dm}^{-3}$ ) at $500 \mathrm{~K}$ in the presence of carbon dioxide, which was introduced as $30 \mathrm{MPa}$ at $323 \mathrm{~K}$ in the reactor and reached to $46 \mathrm{MPa}$ at $500 \mathrm{~K}$, is shown in figure $5(\mathrm{~b}) .1 .4-\mathrm{AHSO}(4.1 \%$ yield) and 2,5-AHSO (0.6\%) were obtained at $1 \mathrm{~h}$, respectively. Both yields increased with increase in reaction time and $21.7 \%$ of $1,4-\mathrm{AHSO}$ and $2.9 \%$ of 2,5-AHSO were obtained for $7 \mathrm{~h}$ treatment. Isosorbide was also obtained from $1.5 \mathrm{~h}$ and the yield became $7.2 \%$ at $7 \mathrm{~h}$. Figure 5 shows that addition of $30 \mathrm{MPa}$ of carbon dioxide enhanced dehydration reaction of sorbitol at $500 \mathrm{~K}$, in which carbon dioxide partial pressure was $46 \mathrm{MPa}$ at the reaction condition. We also studied the effect of introduction of $10 \mathrm{MPa}$ of carbon dioxide separately, and no effect was observed. We have reported that introduction of $10 \mathrm{MPa}$ of carbon dioxide at $323 \mathrm{~K}$ was not effective for sorbitol dehydration at $523 \mathrm{~K}^{10}{ }^{10}$ It was revealed that much higher pressure of $30 \mathrm{MPa}$ is need for enhancement of rate of sorbitol dehydration. We have studied intramolecular dehydration behaviour of several types of diols and triols in aqueous phase between $473 \mathrm{~K}$ and $573 \mathrm{~K}$ and showed that intramolecular dehydration proceeded via $\mathrm{S}_{\mathrm{N}} 2$ type mechanism, in which proton adsorbed on reactant polyols followed by cyclization by a backside attack of the other hydroxyl group. ${ }^{11} \mathrm{We}$ also showed that intramolecular dehydration of diols and triols to cyclic ethers in water at $523 \mathrm{~K}$ were enhanced by addition of $10 \mathrm{MPa}$ of carbon dioxide at $323 \mathrm{~K}$ and that order of dehydration rates depended on the degree of hydroxyl groups (tertiary $>$ secondary $>$ primary
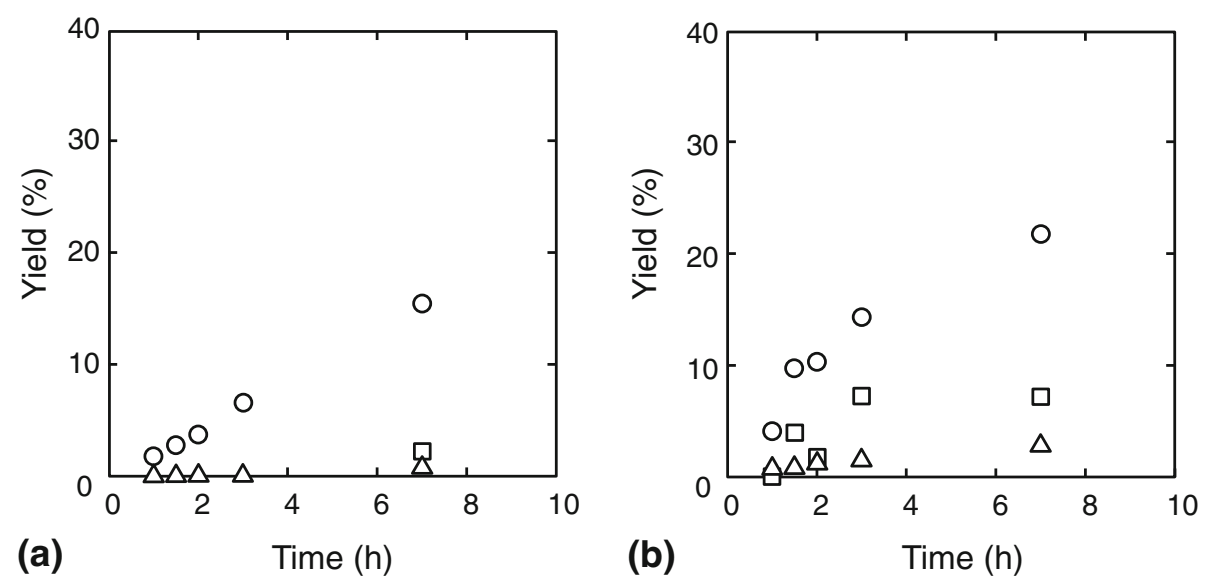

Figure 5. Dehydration of sorbitol in water under (a) argon (0.1 MPa, introduced at room temperature) and (b) carbon dioxide $(30 \mathrm{MPa}$, introduced at $323 \mathrm{~K})$ at $500 \mathrm{~K}$. (०: 1,4-anhydrosorbitol, $\triangle: 2,5$-anhydrosorbitol, and $\square$ : isosorbide). Initial sorbitol concentration was $1.0 \mathrm{~mol} \cdot \mathrm{dm}^{-3}$. 


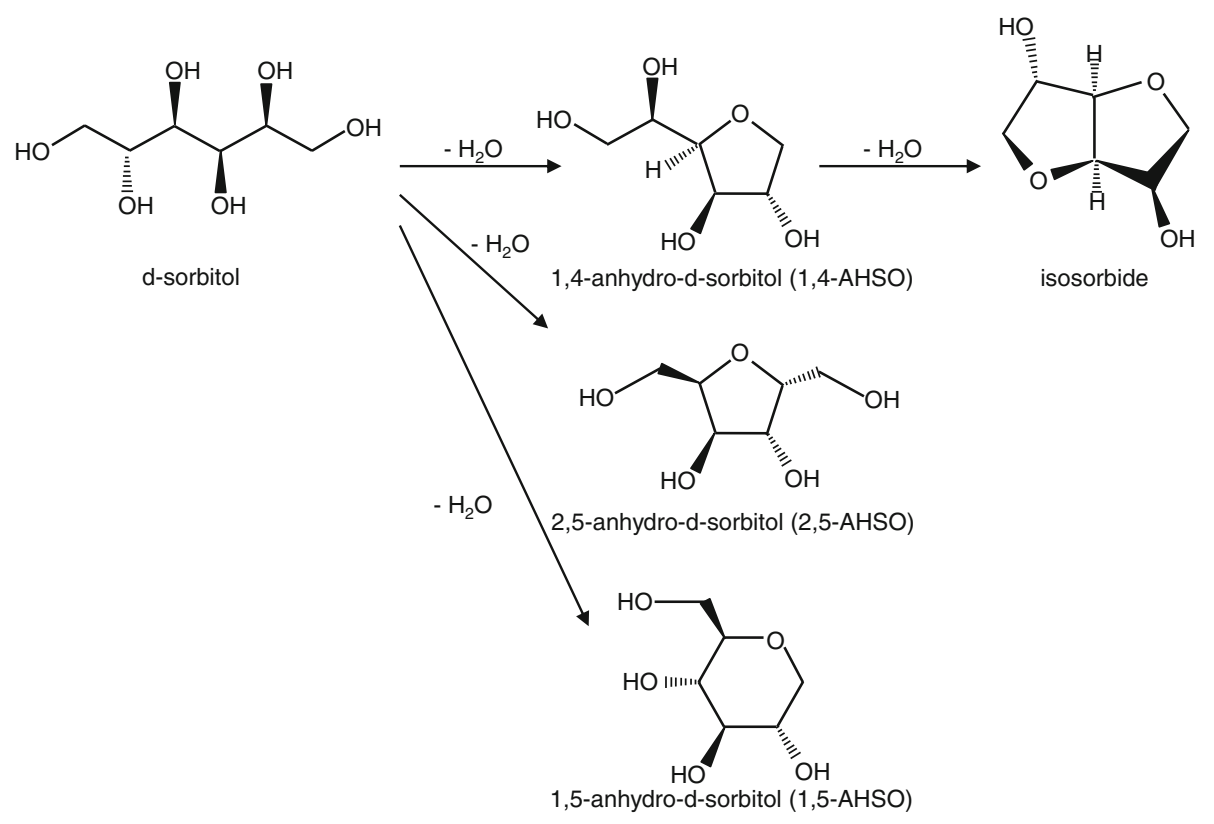

Scheme 2. Dehydration of sorbitol.

alcohols), by the study of dehydration of 1,4butanediol, 2,5-hexanediol, and 2,5-dimethyl-2,5hexanediol. ${ }^{12,13}$ 1,4-AHSO was obtained by dehydration of one water molecule from first position (primary alcohol) and fourth position (secondary alcohol) of hydroxyl groups in sorbitol molecules and 2,5-AHSO was obtained by dehydration of one water molecule from second position (secondary alcohol) and fifth position (secondary alcohol) of hydroxyl groups in sorbitol molecules. From the results of 1,4-butanediol, 2,5-hexanediol, and 2,5-dimethyl-2,5-hexanediol, it was supposable that dehydration of sorbitol in water could be enhanced by addition of $10 \mathrm{MPa}$ of carbon dioxide; however, it did not. Sorbitol molecules are symmetric in polarity because a sorbitol molecule consists of six carbon atoms and each carbon atom has one hydroxyl group, which would be insensitive to the protonation; then the high pressured carbon dioxide was not so effective. Although we did not calculate the amount of protons, we can image that the amount of proton in water phase under $10 \mathrm{MPa}$ of carbon dioxide is not so different from that under $30 \mathrm{MPa}$, indicating that other factors except for proton would contribute to the enhancement of dehydration. Molar amount of $30 \mathrm{MPa}$ of carbon dioxide is estimated to be about one-third of water molecules in the reactor. ${ }^{14} \mathrm{We}$ will carry out phase observation and theoretical calculation of solvation geometry under reaction conditions for understanding the effect of high-pressure carbon dioxide.

\section{Conclusion}

We studied the effect of pressured carbon dioxide on heterogeneous hydrogenation of benzaldehyde and homogeneous dehydration of sorbitol in aqueous phase. Initial hydrogenation rates of benzaldehyde over a charcoal-supported palladium catalyst in water at $313 \mathrm{~K}$ were enhanced by the addition of carbon dioxide. The initial rate increased with an increase in carbon dioxide pressure and became a maximum at $5 \mathrm{MPa}$. Dehydration of sorbitol in aqueous phase proceeded at $500 \mathrm{~K}$ and the initial dehydration rates were enhanced by the addition of $30 \mathrm{MPa}$ of carbon dioxide.

\section{Acknowledgements}

This study was supported by Special Coordination Funds for Promoting Science and Technology 'Development of Sustainable Catalytic Reaction System using Carbon dioxide and Water'.

\section{References}

1. Anastas P T and Zimmerman J B 2003 Environ. Sci. Technol. 37 94A

2. Osada M, Sato T, Watanabe M, Shirai M and Arai K 2006 Comb. Sci. Tech. 178537

3. Arai M, Fujita S and Shirai M 2009 J. Supercritical Fluids $\mathbf{4 7} 351$

4. Hunter S E, Ehrenberger C E and Savage P E $2006 \mathrm{~J}$. Org. Chem. 716229 
5. Rode C V, Joshi U D, Sato O and Shirai M 2003 Chem. Commun. 1960

6. Hiyoshi N, Sato O, Yamaguchi A and Shirai M 2011 Chem. Commun. 4711546

7. Osada M, Sato O, Watanabe M, Arai K and Shirai M 2006 Energy Fuels 20930

8. Yamaguchi A, Hiyoshi N, Sato O, Rode C V and Shirai M 2008 Chem. Lett. 37926

9. Carroll J J, Slupsky J D and Mather A E 1991 J. Phys. Chem. Ref. Data 201201
10. Yamaguchi A, Hiyoshi N, Sato O and Shirai M 2011 Green Chem. 13873

11. Yamaguchi A, Hiyoshi N, Sato O and Shirai M 2011 ACS Catal. 167

12. Yamaguchi A, Hiyoshi N, Sato O, Bando K K and Shirai M 2009 Green Chem. 1148

13. Yamaguchi A, Hiyoshi N, Sato O and Shirai M 2012 Catal. Today 185302

14. Hiyoshi N, Sato O, Yamaguchi A, Rode C V and Shirai M 2013 J. Jpn. Petrol. Inst. 56165 